\title{
EL TRANVÍA DE BOGOTÁ, 1882-1951
}

\author{
Juan Santiago Correa Restrepo* \\ Santiago Jimeno León** \\ Marianela Villamizar Bacca***
}

H1 desarrollo del transporte urbano masivo es consecuencia de nuevas tecnologías de trasporte y tuvo gran impacto en la localización de servicios y vivienda en las ciudades a medida que se desarrollaban nuevos sistemas de transporte para atender el crecimiento urbano. En Europa, esos nuevos sistemas integraron los centros industriales y los distritos de las clases trabajadoras en poblaciones cercanas a las ciudades, aunque esa integración se realizó una década después que en algunas ciudades de Estados Unidos. Por ejemplo, el plan de Loubat para introducirlas en París no tuvo éxito, en parte por la actitud de la administración de la ciudad. Si bien se le autorizó un experimento en 1853, nunca se permitió el tendido de rieles en el centro de la ciudad, lo que rompía la unidad del servicio y retrasó el plan casi dos décadas. En Londres, los intentos de George Francis en 1859 enfrentaron una fuerte oposición porque los rieles se construían por encima del camino y entorpecían el transporte tradicional. Mientras que en Nueva York, John Mason fundó la New York and Harlem Railroad Company en 1832 para conectar la proyectada estación del ferrocarril de Nueva York en Harlem con Albany, y muy pronto esta línea de carros de

* Economista y doctor en Sociología Jurídica, secretario general del cesa y miembro del Grupo de Estudios en Administración del cEsA, [juansc@cesa.edu.co].

** Administrador de Empresas, profesor del CESA, asistente de investigación del Grupo de Estudios en Administración del cesA, [santiago_jimeno@hotmail.com].

*** Profesional en Gobierno y Relaciones Internacionales, asistente de investigación del Grupo de Estudios en Administración del cesa, [nellavillamizar@gmail.com]. Fecha de recepción: 30-09-2016, fecha de modificación: 21-02-2017, fecha de aceptación: 27-04-2017. Sugerencia de citación: Correa, J. S., S. Jimeno L. y M. Villamizar B. "E1 tranvía de Bogotá, 1882-1951", Revista de Economía Institucional 19, 36, 2017, pp. 203-229. DOI: https://doi.org/10.18601/01245996.v19n36.08. 
tracción animal se convirtió en un medio de transporte de pasajeros dentro de la ciudad (McKay, 1976, 14-16).

Europa vivió la segunda revolución industrial desde la segunda mitad del siglo xix; la cual indujo cambios en las fuentes de energía -el vapor fue sustituido por la electricidad- que repercutieron en otros aspectos de la economía y del transporte. De acuerdo con Ebrey (2015), en este periodo se hicieron necesarias nuevas formas de organización del tiempo y del espacio que solo podían ser atendidas con medios de transporte emergentes, como el ferrocarril.

En el caso del tranvía, el tamaño y la complejidad del servicio dependía de aspectos tales como el volumen y la densidad de población, la geografía, el nivel de ingreso, el tamaño del mercado y el capital disponible (Martínez y Mirás, 2015). En Europa, la electrificación de las líneas avanzó lentamente debido a los requerimientos técnicos para producir energía, que hacían más costosas las inversiones. Pero al final, "la electrificación de las líneas significó un incremento de las ganancias por acción y un aumento de los dividendos, aunque también una oportunidad para aumentar la disponibilidad del servicio, suplir la demanda insatisfecha e incentivar a nuevos usuarios" (McKay, 1976).

En América Latina, la adopción del tranvía se inició en Brasil, en 1850 , con vehículos de tracción animal. Río de Janeiro fue una ciudad pionera que adoptó en 1872 la fuerza del vapor en el transporte urbano de pasajeros. En Santiago de Chile, Walton Evans construyó la primera línea en 1858 mediante una concesión, con tecnología y carros similares a los de Nueva York (Pires, 2012). El primer tranvía eléctrico de Suramérica se estableció en Río de Janeiro en 1892, el cual llegó a transformar el paisaje y las características de las ciudades brasileñas. A mediados del siglo xix Ciudad de México se extendía en un área relativamente compacta, y debido a condiciones técnicas inicialmente construyó una red de tranvías de tracción animal para complementar el servicio de ferrocarril, y dio inicio al sistema de tranvías eléctricos en 1900 (Leidenberger, 2011).

La relación entre transporte y crecimiento económico y urbano ha sido muy estudiada, en especial en historia económica e historia urbana, con énfasis en los ferrocarriles y menos acento en el transporte público urbano (tranvías, trolleys y buses). En general, se encuentra que el transporte dinamiza la urbanización y es un factor determinante en la localización de la industria, la vivienda y el comercio. Por ejemplo, en el trabajo de Mirás (2005) sobre la definición urbana de La Coruña entre 1903 y 1962 y su relación con el desarrollo del tranvía, y en el de Tennet (2013), que analiza la construcción y operación del 
sistema de tranvías de York entre 1909 y 1934, en una perspectiva de estrategia corporativa basada en los recursos.

Quizá uno de los trabajos más completos sobre la relación entre crecimiento urbano y transporte público sea el volumen compilado por Divall y Bond (2003), el cual incluye varios estudios de caso que analizan el papel del transporte público urbano en la suburbanización del Reino Unido y su relación con la localización de vivienda obrera y de zonas industriales. En el área del cambio técnico, la mayor parte de la literatura gira en torno al trabajo clásico de McKay (1976), el cual muestra que la introducción de la energía eléctrica en el transporte público catalizó la expansión suburbana, aunque, como señala Tennet, no explica las razones de la desaparición de esta industria hacia la década de 1950 en la mayor parte de Europa, como sucedería también en América Latina.

Desde un enfoque diferente, Schmucki (2010; 2002) analiza la relación entre género y transporte urbano en Alemania después de 1945, rechazando los conceptos preconcebidos de la relación entre género y dicotomía público-privado, y planteando que el transporte público es un espacio socialmente construido donde se manifiestan tensiones de género.

En América Latina se destaca el trabajo de Leidenberger sobre transporte público y cultura política en Ciudad de México (2011), que a través del estudio del tranvía muestra las tensiones políticas y la construcción de ciudad y de Estado durante la primera mitad del siglo $\mathrm{xx}$, en las que prevalecieron los intereses de los transportistas $\mathrm{y}$ una regulación frágil y muy politizada.

Jaramillo y Parias (1995) analizan el desarrollo del tranvía en Bogotá, con base en información financiera de la empresa del tranvía en sus diferentes formas societarias en el periodo 1929-1951. A partir de esa información estudian el cambio de los patrones de desarrollo del sistema del tranvía a una red de transportadores de buses urbanos más flexible, pero más politizada y menos organizada. Por su parte, Esquivel (1996; 1997) analiza la creación y el desarrollo del sistema de tranvías en la ciudad, el impacto del 9 de abril de 1948, cómo se expandió el tranvía y las razones para sustituirlo por un sistema de buses como principal medio de transporte.

Sobre la relación entre desarrollo urbano y sistemas férreos (trenes y tranvías) en Bogotá cabe mencionar el trabajo de Ojeda (2007), que estudia los cambios en la estructura morfológica urbana y la introducción de nuevas tecnologías de transporte, al tiempo que evalúa los efectos del cambio en las dinámicas sociales y culturales provocado por 
lo que ella denomina "manifestaciones de la modernidad". Duquino (2010) revisa las relaciones con los cambios en el modo de producción, el paso de lo que llama capitalismo comercial basado en el modelo rural/agrícola al capitalismo industrial, y argumenta que el tranvía fue un mecanismo de exclusión que favoreció la valorización de las tierras que poseían las élites al norte de Bogotá, en dirección hacia Chapinero, frente a las vías necesarias al sur de la ciudad. Montezuma (2000; 2008) hace un sólido análisis de la relación entre la construcción de la red del tranvía y el cambio en los patrones de crecimiento urbano que venían de la Colonia. Su investigación muestra que hubo un paso a una ciudad lineal que tuvo profundas implicaciones sociales y económicas.

En general, los trabajos mencionados, así como algunas tesis de maestría, se han concentrado en el impacto sobre el modelo de ciudad, desde diferentes perspectivas. Y la mayoría hacen análisis limitados de la operación empresarial y de la relación entre las élites y el desarrollo del transporte en la ciudad.

Este artículo se basa en una revisión exhaustiva de la literatura sobre la historia de Bogotá y del tranvía, en análisis de la prensa de la época y de fuentes primarias publicadas, en particular los Informes de la Gerencia y la Junta Directiva del Tranvía, el Registro Municipal, los acuerdos municipales y documentos oficiales. Así como en una relectura de las fuentes secundarias. Su propósito es analizar, desde la óptica de la historia empresarial, el desarrollo y la estructuración del sistema de tranvías y la interacción entre los actores públicos y privados que participaron en su desarrollo. El artículo se divide en cuatro partes: primero estudia el inicio del sistema a finales del siglo XIX y su impacto en el crecimiento urbano; después analiza los cambios provocados por la municipalización del servicio en 1910; la tercera parte examina el papel de los acreedores en el modelo de administración delegada y la influencia de los competidores del sistema en su declive; termina con algunas consideraciones finales.

\section{LA "BOGOTÁ CITY RAILWAY CO."}

A finales del siglo xIx, la ciudad tenía unos 78.000 habitantes y cubría 203 ha. A comienzos del siglo xx tenía 86.328 habitantes y cubría 320 ha. Gran de este crecimiento fue provocada por la migración a un centro urbano dinámico más que por la tasa vegetativa de crecimiento, que se mantuvo relativamente baja, entre el $1 \%$ y el $2 \%$, frente a una tasa de crecimiento de la población que osciló entre el 4\% y el 5\% en la primera mitad de siglo (Mejía, 2000, 250; Suárez, 2006, 203-205). 
Durante los procesos migratorios de finales del siglo xix y comienzos del xx la mayor parte de los migrantes se ubicó en barrios tradicionales, y solo aparecieron dos barrios nuevos con respecto al ordenamiento colonial: Las Aguas y Las Cruces. Aunque se empezó a esbozar el nacimiento de otros tres: Egipto, La Perseverancia y Chapinero, en ese momento un caserío externo al casco urbano $(\mathrm{Gu}-$ tiérrez, 2007, 11). En 1881 la ocupación urbana se concentró en los barrios de La Catedral, Las Nieves, San Victorino y Santa Bárbara; en los años siguientes hubo una expansión importante, debido en su mayor parte a la migración del campo a la ciudad. En 1918 el 30\% de la población no vivía en estos lugares tradicionales y en 1938 el 40,6\% (Esquivel, 1997, 47).

Aunque el crecimiento urbano fue lento en el siglo xIx, ya empezaba a dirigirse hacia el norte, al caserío de Chapinero, primero como lugar de descanso con grandes quintas y casas de la élite bogotana para luego convertirse, con la llegada del tranvía, en un centro de crecimiento dotado de restaurantes, tiendas de comercio, talleres artesanales, hipódromo, colegios, etc. (Gutiérrez, 2007, 29) ${ }^{1}$. En estricto sentido, Chapinero fue el primer barrio suburbano de Bogotá, con un templo construido en 1875, el Parque de Lourdes, como centro espacial y con una fuente de agua detrás de la iglesia. Después tendría una estación de tranvía para facilitar el transporte, un mercado público y una estación de tren (Zambrano, 2007, 28).

A comienzos de la década de 1880, el establecimiento de un tranvía de tracción animal o de sangre fue una manera de acoplar los medios de transporte tradicionales, mulas o caballos, a la novedad tecnológica del ferrocarril ${ }^{2}$. En este sentido, Bogotá fue pionera en el país cuando se promulgó la Ley 30 de 1881 del Estado de Cundinamarca, la cual previó la concesión para construir un tranvía o ferrocarril de sangre en la ciudad.

E1 14 de octubre de 1882, con base en la Ley 30, se firmó el contrato entre Próspero Gamba Pereira, como representante del Estado de Cundinamarca, y William W. Randall, cónsul norteamericano en Barranquilla y empresario ferrocarrilero de Terranova, para establecer el servicio en Bogotá. De acuerdo con el contrato, este debía ser similar

1 Usamos el término "élite", en particular "élite económica", para designar a un pequeño grupo de personas cuya red de influencias y relaciones les permite controlar propiedades e ingresos, con alta probabilidad de que se cumplan sus decisiones.

2 Aunque durante el siglo XIX en el mundo funcionaron tranvías movidos por máquinas de vapor que daba movimiento a un cable de arrastre, en Colombia solo hay información de un sistema similar en el tranvía de Cúcuta que usaba pequeñas locomotoras para mover los vagones (Arias de Greiff, 1986, 15). 
al de Nueva York (Rodríguez y Núñez, 2003, 33; Suárez, 2006, 139; Aprile, 1983, 83) $)^{3}$. Una vez firmada la concesión, el 30 de octubre de 1883 se fundó la Bogotá City Railway Co. en Nueva York, (Morrison, 2007). El contrato se materializó en el Acuerdo Municipal de Bogotá n. ${ }^{\circ} 22$ de 1882, por el cual la concesión duraría 30 años -luego de los cuales pasaría a ser propiedad de la ciudad-, con una tarifa máxima de 10 centavos por viaje. Daba exenciones tributarias a los materiales que se compraran para construir el tranvía y ofrecía exoneración del servicio militar a los empleados.

Randall vendió los derechos de la concesión al empresario ferrocarrilero Frank W. Allen, quien ordenó 16 tranvías de 2 ejes a la J. G. Brill Co. de Filadelfia, compuestos por ocho carros cerrados, numerados del 1 al 8, y ocho carros abiertos, numerados del 9 al 16, con capacidad de 20 pasajeros. La empresa también se conoció como Ferrocarril de Bogotá (ibíd.). E1 tendido de los rieles y el ensamble de los carros importados estuvo a cargo del ingeniero H. M. James (Gutiérrez, 2007, 70). El servicio se inauguró el 24 diciembre de 1884, con una línea entre el puente de San Francisco (que luego se extrendería hasta la Plaza de Bolívar) hasta San Diego por la Calle Real (hoy carrera 7. a con calle 26), donde tomaba el Camino Nuevo (carrera 13) hasta Chapinero, en una línea de un solo sentido con rieles de madera revestidos en metal ${ }^{4}$, que comenzaba en la estación ubicada en la carrera 13 con calle 57, donde se situaba el depósito de tranvías.

Gráfica 1

Ruta del tranvía, 1884-1890

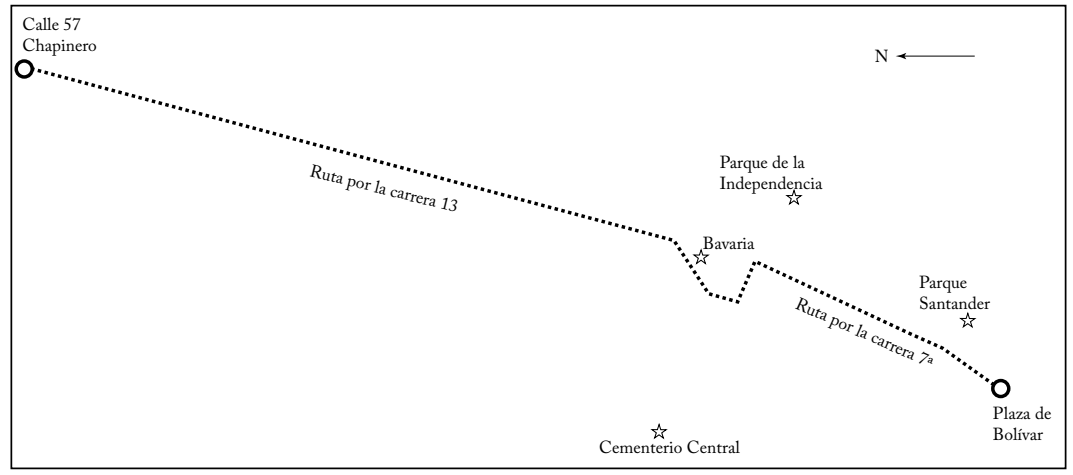

Fuente: Acosta y Baquero (2007) y Morrison (2007).

${ }^{3}$ Contrato autorizado mediante el Acuerdo n. ${ }^{\circ} 22$ del Estado Soberano de Cundinamarca.

${ }^{4}$ Los rieles no siguieron el tendido estándar en Colombia y Estados Unidos en ese momento (la carrilera de una yarda de ancho), sino que usó la trocha métrica. En 1894 se instalaron rieles stándar (Morrison, 2007). 
E1 valor del pasaje se fijó en 2 centavos por trayecto ${ }^{5}$, competitivo frente al de otros medios y que, de acuerdo con Rodríguez y Núñez, logró movilizar en una semana un número mayor de personas que otros medios en los seis meses anteriores a su inauguración (2003, 33-34). La primera ruta era de carácter interurbano, pues recorría un tramo muy corto hasta los extramuros de San Diego, para de allí seguir hasta Chapinero, fuera del casco tradicional. Esta línea fue determinante en la dinámica social y económica entre estos dos núcleos poblacionales.

La segunda línea, que se inauguró 8 años después, conectó la Plaza de Bolívar con la Estación de la Sabana. En 1894 transitaba un carro cada 20 minutos por la vía a Chapinero y el año siguiente cada 10 minutos (Esquivel, 1997, 44). El público empezó a demandar una línea que llegara al barrio Las Cruces por la carrera $7 .{ }^{\mathrm{a}}$, al sur, y otras entre San Victorino, en el occidente, y el barrio Egipto, al oriente (Rodríguez y Núñez, 2003, 36). A pesar del cambio, las quejas sobre la operación, el aseo y el sobrecupo fueron desde entonces una constante y deterioraron la imagen del servicio entre los usuarios. A ello se sumaban demoras de hasta 2 horas, accidentes y la resistencia de las mulas a dar paso, hechos que reforzaron la imagen de mal servicio (Acosta y Baquero, 2007, 12; Rodríguez y Núñez, 2003, 34).

Gráfica 2

Rutas del tranvía, 1900-1910

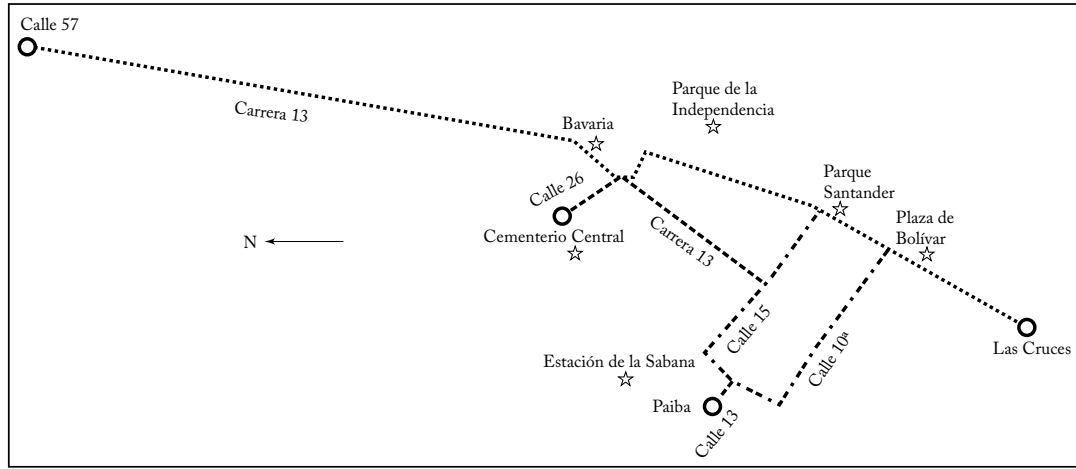

Fuente: Acosta y Baquero (2007) y Morrison (2007).

En ese mismo año el municipio denunció a la empresa por no cumplir lo pactado, es decir, construir las líneas y prestar el servicio como "en

\footnotetext{
${ }^{5}$ Según otras fuentes, el valor del pasaje era de 2, 5 o 10 centavos, aunque el posterior aumento a 5 centavos hace suponer que era de 2 centavos (Montezuma, 2008, 79).
} 
Nueva York", y por no haber hecho el pago final de 12.500 pesos, con el propósito de rescindir el contrato y comprar el tranvía, además de pedir una indemnización para la ciudad. Este proceso fue anulado en un desistimiento mediante el Acuerdo n. ${ }^{\circ} 28$ de 1894 expedido por el Concejo Municipal y se llegó a un nuevo acuerdo con la empresa (El Correo Nacional, 1890; El Heraldo, 1890).

Mediante el Acuerdo n. ${ }^{\circ} 2$ del 28 de enero 1904 del Concejo Municipal se celebró un contrato entre la Bogotá City Railway Company y la ciudad, que autorizó el aumento paulatino del cobro hasta 5 centavos por viaje sencillo y 1 centavo por cada $12^{1 / 2} \mathrm{~kg}$ de carga en carros especiales, destinados para ese fin por la compañía, en viajes sencillos. A cambio, la compañía se comprometió a pagar una anualidad de 1.000 pesos al municipio durante los dos primeros años, con aumentos anuales de 100 pesos a partir del tercer año, así como a aumentar el número de rutas y la frecuencia de los horarios, en particular en los momentos de mayor afluencia de público y en las noches; y, quizá lo más importante, a mejorar el servicio. No obstante, en 1908 la calidad no mejoró y la prensa local seguía publicando numerosas quejas sobre el trato de los postillones a las mulas y los pasajeros, el insuficiente número de carros y la falta de infraestructura en sitios clave (Alcaldía de Bogotá, 2016).

De acuerdo con las noticias de la época, el 7 de marzo un altercado entre un niño y un postillón provocó un enfrentamiento entre la población y Miles R. Martin, uno de los empresarios del tranvía (Rodríguez y Núñez, 2003, 40). En las instalaciones de la empresa, en San Francisco, se reunieron grupos de protesta que lanzaron piedras contra las puertas y ventanas (Pereira, 2011, 93). La campaña de saboteo continuó en las semanas siguientes para evitar que las personas usaran el servicio.

Hay pruebas de que el 20 de marzo, en el almacén Del Día, de propiedad de la familia Liévano, se reunieron Tomás Samper, Félix y Nicolás Liévano, Hernando Holguín y Caro, Carlos Dávila, Francisco Olarte Camacho y otras personas para formar lo que se llamó la Junta Mantenedora del Tráfico, cuyo objetivo era reunir fondos para promover el boicot durante varios meses (Zambrano, 2007,123; Suárez, 2006, 282).

Las protestas y el boicot se acentuaron a medida que se aproximaba la celebración del 20 de julio, y los promotores del boicot aprovecharon la afluencia de gente de fuera de Bogotá que asistía a los festejos del Centenario. En eso días la prensa insistía en el apoyo del boicot y llamaba a no utilizar el servicio (Correa, 2010, 287; Pereira, 2011, 91). 
La exigencia de los propietarios estadounidenses de que la empresa cumpliera los pagos agotó los recursos, y el municipio tuvo que emprender gestiones para comprarla. La ciudad recurrió al financiamiento bancario y a hipotecas de bienes públicos para recaudar el capital necesario ${ }^{6}$. Los empresarios estadounidenses recibieron 800.000 dólares por la compañía, el doble del valor en libros. Pero su insatisfacción se volvió permanente. Culpaban de la movilización contra la compañía a los dueños de la Compañía de Energía Eléctrica de Bogotá por instigarla en busca de beneficios por la total electrificación del sistema (Jaramillo y Parias, 1995, 10; Santos, 2001). El Concejo Municipal aprobó el empréstito para esta negociación entre diferentes bancos y particulares; el Banco de Colombia participó con 121.000 pesos. Además autorizó un empréstito por 240.000 libras esterlinas en los mercados internacionales. La compra culminó el 10 de diciembre de 1910 con la cancelación de 375.000 dólares como última cuota, mediante dos pagos, al City Bank y a Arthur Hugh Frazier, y así empezó el periodo de administración municipal (Rodríguez y Núñez, 2003, 48).

Esa transacción tuvo un impacto importante en el largo plazo. En 1921 se emitieron bonos de tranvía para reconocer las emisiones de títulos de 1910. También se emitieron bonos garantizados por hipotecas sobre el Matadero Público, la Plaza de Carnes, la Plaza Central del Mercado, la casa del antiguo Hotel Francés y el Palacio Municipal, para pagar la deuda del tranvía y ampliar la empresa, por un monto de 823.657 pesos. Igual que en 1910, el Banco de Colombia, a través de Ernesto Michelsen, actuó como intermediario entre los tenedores de bonos y la ciudad (Esquivel, 1997, 55). Cabe aclarar que lo que se municipalizó fue la operación del servicio, no la empresa, pues esta tenía activos obsoletos, y su cobertura y su capacidad operativa eran limitadas.

\section{EL TRANVÍA MUNICIPAL DE BOGOTÁ: UNA APUESTA POR MODERNIZAR EL SERVICIO}

En el momento de la municipalización, la empresa tenía 4 líneas, una planta eléctrica, 180 mulas -la mayoría viejas y débiles-, 9 bueyes, 6 carros eléctricos, uno de ellos con el motor quemado, y 33 carros de pasajeros y carga de tracción animal en estado de deterioro. La red apenas alcanzaba $12 \mathrm{~km}$, dos de ellos electrificados, desde el Parque Santander hasta la calle 26. El trayecto más largo era el de la línea

\footnotetext{
${ }^{6}$ Incluso hizo una colecta pública con ese fin, pero los recursos fueron insuficientes.
} 
original de la Plaza de Bolívar a Chapinero $(6 \mathrm{~km})$; en el tramo de $\mathrm{La}$ Magdalena a Chapinero los rieles y durmientes estaban deteriorados y faltaba balasto. Las tres líneas restantes conectaban la Plaza de Bolívar a la estación del tren $(2 \mathrm{~km})$, la zona del cementerio católico (3 $\mathrm{km}$ ), que estaba en avanzado estado de abandono y no era operable, y La Perseverancia, cerca de la fábrica de Bavaria $(2 \mathrm{~km}$ ) (Jaramillo y Parias, 1995, 11; Rodríguez y Núñez, 2003, 57).

E1 26 de febrero de 1920, el Acuerdo n. ${ }^{\circ} 1$ del Consejo Municipal ratificó la compra de dos lotes en Ubaque por la suma de 10.850 pesos a Fabio González. Así la empresa adquiría las propiedades necesarias para instalar una nueva planta hidroeléctrica. Esta compra fue protocolizada mediante la Escritura Pública n. ${ }^{\circ} 2668$ del 20 de diciembre de 1919, en la Notaría Segunda (Alcaldía de Bogotá, 2016).

Como muestra el cuadro 1, la empresa fue superavitaria durante este periodo y fue un importante recurso fiscal del municipio. El debate giró principalmente en torno a la reinversión de los excedentes o a su traslado a otros gastos del municipio. Además, el excedente operacional fue mayor del $50 \%$ casi todo el periodo.

Cuadro 1

Rendimientos del tranvía, 1911-1929

(Pesos y porcentaje)

\begin{tabular}{lcccc}
\hline Año & Producto bruto & $\begin{array}{c}\text { Gastos de } \\
\text { explotación }\end{array}$ & Producto neto & $\begin{array}{c}\text { Producto neto/ } \\
\text { Producto bruto }\end{array}$ \\
\hline $1910^{*}$ & 44.085 & 14.607 & 29.477 & 66,86 \\
1911 & 178.598 & 86.226 & 92.372 & 51,72 \\
1912 & 196.960 & 93.384 & 103.576 & 52,59 \\
1913 & 230.916 & 108.133 & 122.783 & 53,17 \\
1914 & 269.088 & 119.789 & 149.299 & 55,48 \\
1915 & 282.774 & 120.349 & 162.425 & 57,44 \\
1916 & 304.528 & 130.488 & 174.040 & 57,15 \\
1917 & 346.634 & 152.590 & 194.044 & 55,98 \\
1918 & 345.091 & 159.953 & 185.138 & 53,65 \\
1919 & 401.991 & 177.948 & 224.043 & 55,73 \\
1920 & 511.305 & 244.357 & 266.948 & 52,21 \\
1921 & 516.578 & 250.710 & 265.868 & 51,47 \\
1922 & 595.834 & 279.691 & 316.143 & 53,06 \\
1923 & 635.570 & 297.355 & 338.215 & 53,21 \\
1924 & 666.409 & 401.451 & 264.958 & 39,76 \\
1925 & 735.083 & 511.113 & 223.970 & 30,47 \\
1926 & 763.842 & 429.393 & 334.449 & 43,79 \\
1927 & 853.874 & 470.549 & 383.325 & 44,89 \\
1928 & 919.452 & 574.672 & 344.780 & 37,50 \\
1929 & 1.014 .103 & 652.326 & 361.777 & 35,67 \\
\hline
\end{tabular}

* Corresponde a solo 86 días de operación luego del boicot y la compra de la empresa.

Fuente: Jaramillo y Parias $(1995,19)$ y Junta Administradora del Tranvía Municipal $(1915,15)$. 
En 1920 la longitud de la vía era de 31,76 km, y se aprobó la consecución de un préstamo de 10 millones de pesos para extenderla a otros puntos de la ciudad, el cual parece no haberse conseguido hasta 1924, cuando el cual el municipio obtuvo un préstamo de 10 millones de dólares en el Banco Dillon Read \& Co. Pero, según la información disponible, en 1925 las vías y el tendido eléctrico estaban muy deteriorados y no se habían hecho las inversiones requeridas para ampliar y mantenimer las vías. Muchas veces estas se reparaban con rieles de fabricación local, cuyas características diferían de los rieles importados y provocaban tumbos en el tránsito del tranvía (Rodríguez y Núñez, 2003, 105). Igual ocurría con las líneas eléctricas, que seguían en servicio a pesar de su desgaste y de haber sobrepasado el tiempo de operación. Sin embargo, el uso del tranvía registró un aumento sostenido de cerca de un millón de pasajeros anuales entre 1924 y 1929 (ibíd., 108).

Se hicieron pocas modificaciones a las rutas originales, aunque se ajustaron para extenderlas a ciertos barrios: a la ruta Alameda-Luna Park se le añadió La Hortúa-Iglesia de San Antonio; la ruta PaibaBarrio Primero de Mayo se modificó en sus dos extremos, para salir de Paiba a la Estación de la Sabana por la calle 15, tomar la carrera 7. ${ }^{\text {y }}$ de allí al Primero de Mayo; la ruta Barrio Ricaurte-Calle 22 se acortó para que no saliera de Paiba sino del Ricaurte y terminara en la calle 22 y no en San Diego; y la del Matadero Público empezó a funcionar con una transferencia desde Paiba hasta el edificio en la carrera 30 (ibíd., 108-109).

Gráfica 3

Rutas del tranvía, 1920-1930

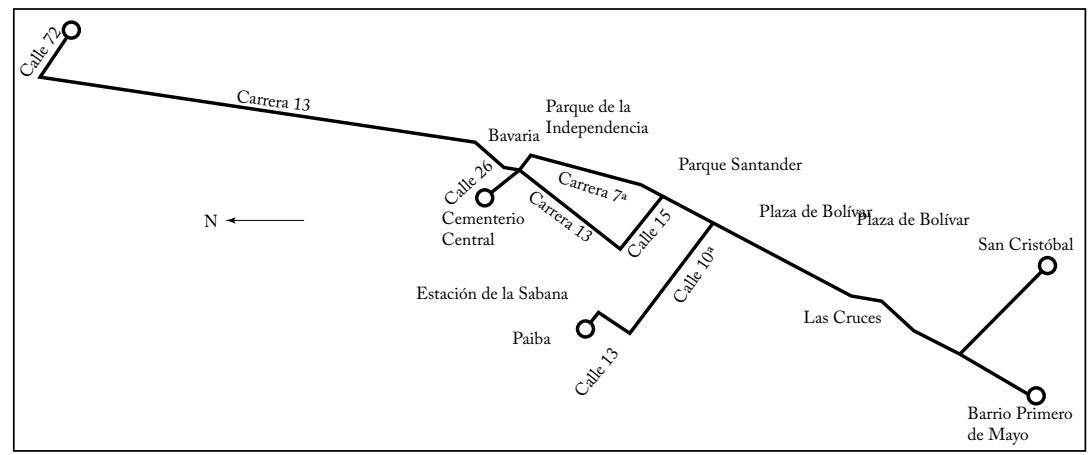

Fuente: Acosta y Baquero (2007) y Morrison (2007). 
Los nuevos barrios obreros terminaron careciendo de servicios de transporte adecuados; además, se construían en zonas aisladas del casco urbano, en lotes de las antiguas fincas carentes de servicios. No era viable ampliar el servicio en 1929 , cuyo costo era de $14.967,35$ pesos $/ \mathrm{km}$, con tarifas de 5 centavos para el público en general o de 2,5 centavos para los obreros (ibíd., 109).

Como indica el cuadro 2, entre 1911 y 1928 aumentó el uso del sistema todos los años, salvo en 1917 , cuando se redujo el $0,1 \%$, aunque luego repuntó significativamente. No obstante, el aumento de los viajes per cápita muestra un rezago en todos los años frente al crecimiento bruto del uso del sistema. Esto significa que, si bien aumentaba la población, ese aumento no se traducía en un mayor uso del tranvía, el cual, como se verá, debía competir con los buses en las zonas de mayor uso del servicio.

Cuadro 2

Producto bruto y gastos de explotación por pasajero, 1911-1929 (Centavos)

\begin{tabular}{lcc}
\hline Año & Producto bruto/pasajero & Gasto de explotación/pasajero \\
\hline 1911 & 5,035 & 2,431 \\
1912 & 5,067 & 2,402 \\
1913 & 5,056 & 2,368 \\
1914 & 5,053 & 2,250 \\
1915 & 5,160 & 2,196 \\
1916 & 5,022 & 2,152 \\
1917 & 5,020 & 2,210 \\
1918 & 5,005 & 2,320 \\
1919 & 5,003 & 2,215 \\
1920 & 5,025 & 2,401 \\
1921 & 4,961 & 2,408 \\
1922 & 5,000 & 2,347 \\
1923 & 5,018 & 2,348 \\
1924 & 4,978 & 2,999 \\
1925 & 5,100 & 3,546 \\
1926 & 5,076 & 2,854 \\
1927 & 5,064 & 2,790 \\
1928 & 4,700 & 2,938 \\
1929 & 5,088 & 3,273 \\
\hline
\end{tabular}

Fuente: Jaramillo y Parias $(1995,24)$.

El cuadro 3 muestra que el uso de la capacidad instalada apenas creció, bien sea que se mida por la relación entre puestos disponibles y población o por viajes per cápita. Es decir, aunque el parque aumentó, apenas compensó el crecimiento demográfico.

E1 Tranvía Municipal de Bogotá funcionó entre 1910 y 1929 con dos áreas operativas: administrativa y técnica. La primera incluía la junta administradora, la gerencia, el contador-secretario, el tesorero y 
el ingeniero. Dependiendo del momento específico de ese periodo, la gerencia dependió de la junta o del Concejo Municipal (Rodríguez y Núñez, 2003, 49). Entre 1910 y 1923 hubo cambios continuos en el manejo administrativo por decisión del Concejo, en particular con respecto a los nombramientos, la composición y el funcionamiento de la junta administradora y la gerencia; en una puja permanente entre el Concejo y la junta por el control de la empresa (ibíd.).

Antes de la compra en 1910, el Concejo había ordenado, mediante el Acuerdo Municipal n. ${ }^{\circ} 27$ de 1910, que la junta que controlara la empresa tras la adquisición estuviese compuesta por 10 particulares del sector comercio, con periodos de 3 años, y que diesen garantías en dos aspectos: aceptación de la ciudadanía y alejamiento de la influencia política. Según el acuerdo, la junta nombraría el gerente, por un periodo igual al de sus miembros. El primer gerente provisional, nombrado en septiembre de 1910 siguiendo esta norma, fue Tomás Samper. Pocos días después, el Concejo promulgó el Acuerdo Municipal n. ${ }^{\circ}$ 31 de 1910, que autorizaba la reelección indefinida de los miembros de la junta, y el gerente pasó a ser un cargo de libre nombramiento y remoción (Rodríguez y Núñez, 2003, 50; Ortega, 1923, 658).

Cuadro 3

Capacidad y utilización del tranvía, 1911-1930

\begin{tabular}{lcccccc}
\hline Año & Pasajeros & $\begin{array}{c}\text { Número } \\
\text { de carros }\end{array}$ & Población & $\begin{array}{c}\text { Puestos } \\
\text { ofrecidos* }\end{array}$ & $\begin{array}{c}\text { Puestos/ } \\
\text { población }\end{array}$ & $\begin{array}{c}\text { Viajes per } \\
\text { cápita }\end{array}$ \\
\hline 1911 & 3547 & 27 & 121.257 & 675 & 0,006 & 0,03 \\
1912 & 3887 & 27 & 124.780 & 675 & 0,005 & 0,03 \\
1913 & 4567 & 29 & 128.406 & 725 & 0,006 & 0,04 \\
1914 & 5325 & 31 & 132.137 & 775 & 0,006 & 0,04 \\
1915 & 5480 & 32 & 135.977 & 800 & 0,006 & 0,04 \\
1916 & 6064 & 34 & 139.928 & 850 & 0,006 & 0,04 \\
1917 & 6905 & 33 & 143.994 & 825 & 0,006 & 0,05 \\
1918 & 6895 & 33 & 150.099 & 825 & 0,005 & 0,05 \\
1919 & 8035 & 32 & 156.463 & 800 & 0,005 & 0,05 \\
1920 & 10176 & 30 & 163.097 & 750 & 0,005 & 0,06 \\
1921 & 10413 & 31 & 170.012 & 775 & 0,005 & 0,06 \\
1922 & 11916 & 36 & 177.221 & 900 & 0,005 & 0,07 \\
1923 & 12666 & 41 & 184.735 & 1025 & 0,006 & 0,07 \\
1924 & 13387 & 43 & 192.528 & 1075 & 0,006 & 0,07 \\
1925 & 14412 & 44 & 200.244 & 1100 & 0,005 & 0,07 \\
1926 & 15047 & 46 & 209.244 & 1150 & 0,005 & 0,07 \\
1927 & 16863 & 53 & 218.116 & 1325 & 0,006 & 0,08 \\
1928 & 19561 & 56 & 227.364 & 1400 & 0,006 & 0,09 \\
1929 & 19932 & 60 & 240.000 & 1500 & 0,006 & 0,08 \\
1930 & 18329 & 72 & 244.000 & 1800 & 0,007 & 0,08 \\
\hline
\end{tabular}

* Se corrigieron las cifras de población. Esquivel calculó el número de puestos sobre carros abiertos de menor capacidad: 25 pasajeros sentados.

Fuente: Esquivel (1997, 71). 
Después de este cambio, el 4 de enero de 1924 se posesionó como gerente de la empresa Samuel Montaña, quien sucedió a Nemesio Camacho en ese cargo. En ese momento, la empresa tuvo dificultades internas que deterioraron el clima laboral; en esas condiciones, un llamado de atención disciplinario a un inspector y a un conductor que no llevaban el registro de pasajeros de manera adecuada terminó en explicaciones públicas del gerente el 13 de marzo, y en una carta abierta de algunos empleados el 16 de marzo, en la que se desligaban de un grupo que llamaba a la huelga. E1 20 de abril algunos conductores de la línea de Chapinero no encontraron su nombre en la nómina, supusieron que el rumor de despidos era cierto y suspendieron el servicio; los conductores de otras líneas siguieron su ejemplo horas después (Rodríguez y Núñez, 2003, 89).

El superintendente, un español de apellido Castillo y García que se había granjeado la fama de violento y arbitrario con los trabajadores, llegó a las 3:30 p.m. a los depósitos en Chapinero, y durante la discusión con los conductores le disparó al conductor Plinio Cárdenas, quien luego moriría en la Clínica de Marly. El superintendente fue arrestado por la policía, no sin que antes fuese golpeado por los trabajadores (ibíd., 90). Ese hecho provocó una reacción de los habitantes de Chapinero, de los empleados del tranvía y en general de todos los bogotanos, quienes, a pesar del despido de Castillo y García y de Ernesto Mejía (jefe de tráfico), del reintegro de los conductores excluidos de la nómina y de la firma de un compromiso para reanudar operaciones, paralizaron el servicio en toda la ciudad. Los empleados organizaron una marcha por la calle 26 y la carrera $7 .{ }^{\text {a }}$ hasta la Casa del Pueblo en la calle 2. ${ }^{\text {a }}$, donde obtuvieron el respaldo del Sindicato Central Obrero de Colombia, que los asesoró para formar una junta de reclamación compuesta por empleados de todas las líneas, los talleres, representantes del sindicato y de la Asociación de Obreros sin Trabajo (ibíd.).

E1 memorando de reclamación tenía 22 puntos, que incluían la destitución del gerente y de varios empleados de distinto nivel, indemnizaciones y garantías para los empleados, que no podrían ser víctimas de represalias de la administración. E1 23 de abril, luego de varios días de negociaciones con el ministro de Industrias, el secretario del Ministerio, el jefe de la Oficina del Trabajo, el gobernador de Cundinamarca, el alcalde de Bogotá, el gerente de la empresa, los miembros de la junta administradora, los representantes y abogados de los sindicatos de tranviarios y el asesor del Sindicato Central de Obreros, se logró un acuerdo que reconocía la mayoría de las recla- 
maciones (ibíd., 91). El Acuerdo del Concejo Municipal n. 47 de noviembre de 1924 ordenó que, una vez canceladas las deudas bancarias que afectaban las rentas de la empresa, el Concejo nombrara 3 miembros de la junta administradora. E1 26 de diciembre, el Concejo modificó su carácter de empresa independiente y la convirtió en un departamento de las Empresas Municipales de Bogotá (ibíd., 92).

La dirección de las Empresas Municipales de Bogotá tendría a su cargo el manejo autónomo del acueducto, el tranvía y las plantas eléctricas municipales. Estaría conformada por un interventor de obras, que fue designado como presidente, y tres personas elegidas por el Concejo Municipal por un periodo de tres años. En 1925 se denunciaron irregularidades y negligencia en el manejo de los tiquetes del tranvía, que dieron lugar a fraudes en el recaudo. Esto se descubrió porque el valor nominal de los tiquetes recibidos por los pasajeros era mayor que el de los tiquetes vendidos, lo cual solo podía ocurrir con emisiones falsas, ventas que no entraban en caja o negligencia en el manejo de los recursos (ibíd., 93).

Debido a de estos problemas, en 1926 el Concejo decidió separar, mediante el Acuerdo n. ${ }^{\circ} 5$ del 3 de mayo, el manejo operativo del tranvía y del acueducto, pero mantener unificado el manejo financiero en una unidad de hacienda. Sin embargo, en diciembre del mismo año, mediante el Acuerdo Municipal n. ${ }^{\circ}$ 68, modificó la dirección de las Empresas Municipales para que estuviese integrada por un interventor y dos miembros designados por el Concejo que administrarían el acueducto y el tranvía, suprimió el cargo de hacienda y distribuyó sus funciones entre estos dos miembros. Esa organización se mantuvo hasta 1929 (Alcaldía de Bogotá, 2016).

E1 23 de enero de 1929 se nombró como gerente del tranvía a Hernando de Velasco ${ }^{7}$, quien se desempeñaba como secretario de gobierno de la alcaldía, un nombramiento que la prensa consideró "sorpresivo", pues de Velasco no figuraba entre los posibles sucesores de José Arturo Hernández, quien había sido nombrado ministro de obras públicas por Abadía Méndez. Según la prensa de la época, el nombramiento fue resultado de reuniones sostenidas entre el "estado mayor de la antigua rosca municipal", y apoyado por Alejandro Osorio, gerente del acueducto (El Tiempo, 1929).

Osorio y de Velasco hacían parte del grupo político de José Arturo Hernández y Ruperto Melo, quienes controlaban buena parte del manejo de las empresas públicas de la ciudad y a quienes se responsabilizaba de su preocupante situación financiera. El alcalde

7 Cuñado del presidente Abadía Méndez. 
conservador Luis Augusto Cuervo comenzó a discutir la necesidad y la legalidad de algunos de los negocios que habían llevado a cabo, lo que provocó una reacción fuerte de ellos y su posterior destitución (Rodríguez y Núñez, 2003, 96).

El gobernador Ruperto Melo destituyó al alcalde Cuervo por denunciar la quiebra de las Empresas Municipales y las deficiencias en los servicios públicos, lo que suscitó protestas contra el ministro de obras públicas, José Arturo Hernández (apodado “Chichimoco”),y contra el presidente Abadía Méndez. La movilización de respaldo al alcalde del 5 de junio de 1923 culminó con una congregación de apoyo frente a su casa. Al día siguiente la multitud amenazó con iniciar un boicot al tranvía si no se restituía el alcalde; por orden del gobierno, el general Cortés Vargas movilizó el ejército en una operación que produjo los primeros heridos. Esto incentivó nuevas movilizaciones enardecidas por esa operación y por el recuerdo reciente de la Masacre de las Bananeras por tropas al mando del mismo oficial. A esas movilizaciones se unieron líderes políticos como Jorge Eliécer Gaitán y Federico Lleras Acosta, así como el movimiento estudiantil (ibíd., Esquivel, 1996, 31).

En las protestas del 7 de junio murió en forma accidental Gonzalo Bravo Páez, un estudiante conservador que no participaba en la manifestación. La presión popular aumentó y Abadía Méndez tuvo que aceptar la renuncia del gabinete, y retirar al general Cortés Vargas y al ministro de guerra, Ignacio Rengifo. También sustituyó al alcalde y al gobernador, lo que truncó la carrera política de Ignacio Rengifo, José Arturo Hernández y la "rosca municipal". Como gerente del tranvía se nombró a Manuel Vicente Ortiz y del acueducto a Alfonso Araújo, opositores políticos de los funcionarios recién destituidos (Rodríguez y Núñez, 2003, 96; Suárez, 2006, 145). Los problemas, los cambios y las dificultades operativas incentivaron a varios empresarios privados a competir con el tranvía poniendo en servicio buses hacia y en los barrios obreros, lo que suscitó intentos infructuosos de la administración del tranvía para prohibir su operación, aumentar aranceles o limitar sus rutas (Rodríguez y Núñez, 2003, 110).

Ante las dificultades creadas por la competencia y las exigencias de los bancos acreedores con la ciudad, el Concejo decidió que esos bancos -Bogotá, Colombia y Central Hipotecario- tuvieran el control de las empresas de tranvía y acueducto. Así dio inicio, mediante el Acuerdo del Concejo n. ${ }^{\circ} 15$ de agosto de 1929, a lo que se conoció como administración delegada (Alcaldía de Bogotá, 2016). En este periodo hubo una creciente politización de la administración del tran- 
vía y la empresa se usó como bastión político y burocrático; además, aumentó la capacidad de movilización de sus trabajadores.

\section{LA ADMINISTRACIÓN DELEGADA}

Como resultado del paso a la administración delegada, la dirección de la empresa se trasladó a una junta con gran autonomía fiscal y administrativa respecto de la Alcaldía y el Concejo. Los agentes privados eran mayoría en la junta, compuesta así: un representante del alcalde y uno del Concejo; tres representantes de los principales bancos acreedores (de Bogotá, de Colombia y Central Hipotecario). La junta, con un periodo de dos años, nombraba al gerente del acueducto y al del tranvía (Jaramillo y Parias, 1995, 25).

A finales de 1930 se decidió suspender la producción propia de energía con la planta a vapor, ya muy deteriorada, y empezar a comprarla directamente a las Empresas Unidas de Energía Eléctrica, a 2 centavos el kw frente a los 3 centavos por kw que costaba operarla con carbón. Además, la empresa puso en operación dos convertidores adicionales a los dos que ya tenía; así quedó con una capacidad instalada de 1.200 kw (Rodríguez y Núñez, 2003, 138).

El cuadro 4 muestra que la tasa anual de crecimiento de los pasajeros entre 1929 y 1939 fue volátil, aunque la población creció todos los años, de modo que el servicio no cubría las necesidades provocadas por ese crecimiento. Así mismo, aunque se hicieron esfuerzos para reducir los costos de operación al comienzo del periodo, después volvieron a crecer, de modo que la relación entre producto bruto y neto fue en promedio del $20,9 \%$.

Cuadro 4

Pasajeros del tranvía y población de Bogotá, 1929-1939

\begin{tabular}{lcccc}
\hline Año & Pasajeros anuales & $\begin{array}{c}\text { Tasa } \\
(\%)\end{array}$ & Población & $\begin{array}{c}\text { Viajes por cada } \\
\text { mil habitantes }\end{array}$ \\
\hline 1929 & 19.932 & 1,9 & 227.364 & 87,67 \\
1930 & 18.329 & $-8,7$ & 237.004 & 77,34 \\
1931 & 18.502 & 0,9 & 247.053 & 74,89 \\
1932 & 17.755 & $-4,2$ & 257.528 & 68,94 \\
1933 & 19.565 & 9,3 & 268.447 & 72,88 \\
1934 & 22.639 & 13,6 & 279.829 & 80,90 \\
1935 & 23.764 & 4,7 & 291.694 & 81,47 \\
1936 & 26.298 & 9,6 & 304.062 & 86,49 \\
1937 & 29.586 & 11,1 & 316.954 & 93,34 \\
1938 & 31.241 & 5,3 & 330.312 & 94,58 \\
1939 & 32.166 & 2,9 & 348.123 & 92,40 \\
\hline
\end{tabular}

Fuente: Jaramillo y Parias $(1995,27)$. 
Los costos laborales aumentaron debido a varias razones, entre ellas al desarrollo de nuevas políticas laborales durante los gobiernos liberales, en particular durante el primer gobierno de Alfonso López Pumarejo (1934-1938), así como al crecimiento y fortalecimiento del sindicalismo, que dio mayores posibilidades de presión y negociación (Ocampo, 2007), así como a decisiones administrativas presionadas por los políticos locales. La tarifa se mantuvo congelada y se siguieron desviando recursos operacionales a otras entidades del municipio.

En la década anterior algunos hechos mostraron la capacidad de acción de los empleados de la empresa, como la huelga de enero de 1926 para exigir mejores sueldos y condiciones de trabajo. Pero con un gobierno conservador esa huelga fracasó por la represión de la policía y el ejército. Durante el gobierno de López Pumarejo, la empresa empezó a reconocer beneficios laborales, pagos por incapacidad, hospitalizaciones, medicinas, accidentes de trabajo, bonos por tiempo de servicio y vacaciones. Pero a pesar del ambiente reformista, la empresa adoptó una política policiva antisindical, persiguió a los líderes más críticos y promovió a los afines a la empresa, sin mayor efecto sobre los costos laborales (ibíd., 39-41).

La competencia con los buses se acentuó. En 1925 Arturo Manrique importó 6 buses, que eventualmente fueron comprados por el tranvía, además de otros que importó para evitar la competencia y canalizar el servicio hacia la empresa. En 1927 Antonio Puerto inició un servicio con 20 buses que luego compró la empresa del tranvía, aunque solo estuvieron en operación un año por la dificultad para conseguir repuestos. Pero el principal inconveniente fue la proliferación de transportadores espontáneos que aprovechaban las deficiencias del servicio y la falta de normatividad para adaptar chasises de camiones con carrocerías armadas en talleres locales para prestar el servicio en rutas y horarios irregulares (ibíd., 43).

Como indica el cuadro 5, el servicio de buses afectó el porcentaje de pasajeros movilizados en tranvía, en particular desde 1929, y con mayor intensidad en la década de 1940.

Los transportadores se empezaron a organizar en cooperativas en 1934 para hacer frente al municipio y oponerse a la reglamentación sobre condiciones mínimas de servicio que se intentaba imponer: rutas regulares y normas de servicio. Esas cooperativas se organizaron al amparo de la Ley 134 de 1931. Una de las primeras que se crearon, aunque de corta duración, fue la Cooperativa de Buses de Santa Fe, a la que siguieron la Cooperativa de Buses Ltda. (1934), la Cooperativa de Lubricantes y Transportes Ltda. (1936), la Asociación Cooperativa de 
Transporte Urbano (1939), la Unión Urbana de Transportes (1939), la Unión Comercial de Transportes (1940), los Transportes Santa Lucía (1945) y las Flotas Usaquén y Fontibón (1945). Por su parte, en 1932 se creó la Superintendencia de Sociedades Cooperativas, que primero dependía del Ministerio de Industrias y en 1938 fue transferida al de Trabajo, en una estrategia para fomentar el movimiento solidario (Pérez, 2009, 6; Quijano y Reyes, 2004, 204; Baquero, 2009, 146-147).

Cuadro 5

Movilización de pasajeros en buses y en tranvía, 1927-1951

\begin{tabular}{|c|c|c|c|c|c|c|}
\hline \multirow[b]{2}{*}{ Año } & \multirow[b]{2}{*}{ Buses } & \multirow{2}{*}{$\begin{array}{c}\text { Carros de } \\
\text { tranvía }\end{array}$} & \multicolumn{3}{|c|}{ Pasajeros (miles) } & \multirow[b]{2}{*}{$\begin{array}{c}\text { Uso del } \\
\text { tranvía (\%) }\end{array}$} \\
\hline & & & Buses & Tranvía & Total & \\
\hline 1927 & 55 & 48 & 4.534 & 16.863 & 21.397 & 78,8 \\
\hline 1928 & 68 & 56 & 5.857 & 19.561 & 25.418 & 77,0 \\
\hline 1929 & 150 & 63 & 13.500 & 19.932 & 33.432 & 59,6 \\
\hline 1930 & 176 & 72 & 16.551 & 18.329 & 34.880 & 52,6 \\
\hline 1931 & 144 & 73 & 14.123 & 18.502 & 32.625 & 56,7 \\
\hline 1932 & 163 & 74 & 16.645 & 17.755 & 34.400 & 51,6 \\
\hline 1933 & 171 & 75 & 18.152 & 19.565 & 37.717 & 51,9 \\
\hline 1934 & 151 & 75 & 16.639 & 22.639 & 39.278 & 57,6 \\
\hline 1935 & 266 & 75 & 30.385 & 23.764 & 54.149 & 43,9 \\
\hline 1936 & 199 & 87 & 23.536 & 26.298 & 49.834 & 52,8 \\
\hline 1937 & 211 & 89 & 25.807 & 29.586 & 55.393 & 53,4 \\
\hline 1938 & 222 & 88 & 28.049 & 31.241 & 59.290 & 52,7 \\
\hline 1939 & 245 & 92 & 31.944 & 32.166 & 64.110 & 50,2 \\
\hline 1940 & 305 & 91 & 44.793 & 30.721 & 75.514 & 40,7 \\
\hline 1941 & 390 & 95 & 52.823 & 30.902 & 83.725 & 36,9 \\
\hline 1942 & 428 & 90 & 61.014 & 31.816 & 92.830 & 34,3 \\
\hline 1943 & 428 & 91 & 65.380 & 37.544 & 102.924 & 36,5 \\
\hline 1944 & 414 & 94 & 70.669 & 43.448 & 114.117 & 38,1 \\
\hline 1945 & 372 & 93 & 75.108 & 51.499 & 126.607 & 40,7 \\
\hline 1946 & 506 & 93 & 80.270 & 59.751 & 140.021 & 42,7 \\
\hline 1947 & & 89 & 99.075 & 56.463 & 155.538 & 36,3 \\
\hline 1948 & & 90 & 132.535 & 50.478 & 183.013 & 27,6 \\
\hline 1949 & & 105 & 151.873 & 51.042 & 202.915 & 25,2 \\
\hline 1950 & & 103 & 173.375 & 51.605 & 224.980 & 22,9 \\
\hline 1951 & & 118 & 200.920 & 48.525 & 249.445 & 19,5 \\
\hline
\end{tabular}

Fuente: Jaramillo y Parias (1995, 48 y 59); Baquero (2009, 129, 148 y 171); Registro Municipal (1933, 302), y Rodríguez y Núñez (2003, 134).

No obstante, en ese periodo se ampliaron las líneas del tranvía. En 1932 se extendieron hacia el barrio Colombia (calle 68 con carrera 24). Hacia el suroriente, el tranvía llegó hasta el barrio 20 de Julio, pero no se hizo ningún esfuerzo para prestar el servicio a los barrios de la parte alta de la localidad de San Cristóbal. Hacia el suroccidente, se extendió a los barrios Santander y Libertador (carrera 27 con calle 31 sur). Hacia el sur del Luna Park se amplió la red a los barrios Restrepo, Olaya Herrera, Centenario, Santander y Libertador. Además, se 
construyó una línea por la carrera 11 , entre la calle 10 y la $1 .^{a}$, quizá para enlazar el servicio entre las líneas del centro y del norte que se articulaban en este punto (Acosta y Baquero, 2007, 26-27).

Por otra parte, aumentaron los vínculos entre los transportadores y el partido liberal, pues se consideraba que el tranvía era un fortín burocrático conservador. De modo que los intereses de los transportadores pasaron a ser parte de la política liberal y creció el número de concejales liberales que eran transportadores privados. En 1936, el alcalde de la ciudad, Jorge E. Gaitán, promulgó el Decreto 290, que suprimió el tránsito del tranvía en algunas vías y cedió las rutas a los buses, aunque los carros del tranvía aumentaron con la compra de 12 vehículos de 12 escaños (Jaramillo y Parias, 1995, 46; Baquero, 2009, 149; Esquivel, 1996, 29).

El éxito de los buses en la competencia con el tranvía no se debió a condiciones técnicas favorables, sino a que los buses operaban con condiciones laborales más favorables y muchos eran conducidos por el mismo dueño. Además, no incurrían en costos de construcción y mantenimiento de las vías; tampoco pagaban seguros, ni prestaciones salariales, entre otras ventajas (Jaramillo y Parias, 1995, 52).

En 1936 la empresa aumentó el número de carros en servicio, con 8 tranvías de perfil aerodinámico, cerrados y con puerta central. Por su techo plateado, se empezó a llamarlos "Lorencitas", por las canas de doña Lorencita Villegas, esposa del presidente Eduardo Santos. En esa década se hizo evidente la actitud de la administración del tranvía de no apalancar el crecimiento del sistema, lo que favorecía la competencia de los buses, como quedó claro años más tarde, cuando el Acuerdo n. ${ }^{\circ} 10$ de 1946 decidió modernizar el tranvía usando trolleys y buses (Baquero, 2009, 174-175; Alcaldía de Bogotá, 2016).

Durante la Segunda Guerra Mundial, la empresa mostró una recuperación porque las empresas de buses no podían conseguir en forma regular los repuestos de los vehículos, en particular piezas y llantas importadas imposibles de adquirir en estos años. Aunque el tranvía sufrió ese mismo problema, logró operar con materiales refaccionados, ampliar el periodo de recambio y el uso intensivo de rutas y materiales. Su experiencia en la operación y la disponibilidad de talleres propios que podían producir y adaptar el material le permitieron recuperar parte de la demanda perdida, y aunque operaba con costos más altos, los compensó con un mayor uso del servicio (Prieto, 2005, 40; Baquero, 2009, 171).

En 1943, el alcalde Sanz de Santamaría propuso un plan para municipalizar el transporte de la ciudad. Ya había hecho contactos 
con bancos para obtener un préstamo de un millón de pesos con el fin de comprar y mejorar los buses privados existentes y comprar 40 más para las rutas de mayor demanda, aunque el plan no se llevó a cabo debido a la movilización popular y a la alteración del orden público que provocó la anulación de la elección de un sindicalista a la Cámara de Representantes (Jaramillo y Parias, 1995, 70).

Entre 1942 y 1943 se decidió no actualizar ni modernizar el servicio, y llevar a reserva el producto neto de la empresa con la idea de una reconversión futura a trolleys y buses de gasolina. Un proyecto sobre el cual se discutía desde 1928, pero cuyos estudios siempre mostraban que la operación de los buses era más costosa (Jaramillo y Parias, 1995, 71).

E1 9 de abril de 1948 hubo ataques al tranvía a causa del Bogotazo. Según Jacques Aprile, más que una manifestación popular contra el poder establecido, esa destrucción fue promovida por los transportadores privados y, según testimonios, los ayudantes de los buses esparcían la gasolina con la que incendiaron los carros. Una actitud que parece haber sido sistemática, al menos en el caso de dos empresas, Buses Rojos y Buses Amarillos, la primera asociada a la Compañía Importadora de Leonidas Lara \& Cía., que importaba buses y tenía acciones en ella. Sus dueños eran propietarios de una estación de gasolina culpada de regalar combustible ese día $(1983,90)$.

De acuerdo con un testimonio recogido por Aprile a Francisco Triana, gerente del tranvía, durante el Bogotazo se quemaron $34 \mathrm{ca}-$ rros, de lo que responsabilizó a las cooperativas de buses, las cuales, a pesar de haberse demostrado su responsabilidad, no fueron castigadas, según él, por sus nexos con algunos concejales (ibíd., 91).

Se destruyeron carros del tranvía en cuatro lugares principales: la Plaza de Bolívar (7 u 8 carros), el Parque de Santander (3 carros), en la Avenida Jiménez a la altura de la Gobernación (aparentemente 4 carros), y en la carrera 7.a al frente de la oficina de Gaitán (3 carros). Es decir, unos 17 o 18 carros en los lugares de mayor intensidad de los ataques, aunque no todos fueron destruidos por completo (ibíd., 89). Si bien las cifras son contradictorias y no hay consenso sobre ellas, la estimación más pesimista es que ese día se averió o perdió cerca del 35\% del parque de la empresa: un gran golpe, pero no un obstáculo insalvable para seguir funcionando en los días siguientes.

La respuesta a esta situación fue rápida; al día siguiente se compraron 3 buses trolley, 16 de gasolina y 74 tranvías. El 15 de mayo de 1948 se anunció la compra de 20 buses de gasolina marca Mack con capacidad de 37 pasajeros, y se anunció la llegada de 17 trolley 
buses para cubrir el servicio entre la Avenida Chile y San Francisco, que empezarían a operar en los meses siguientes, a medida que se instalaran las líneas eléctricas (Rodríguez y Núñez, 2003, 136).

Gráfica 4

Rutas del tranvía 1940-1951

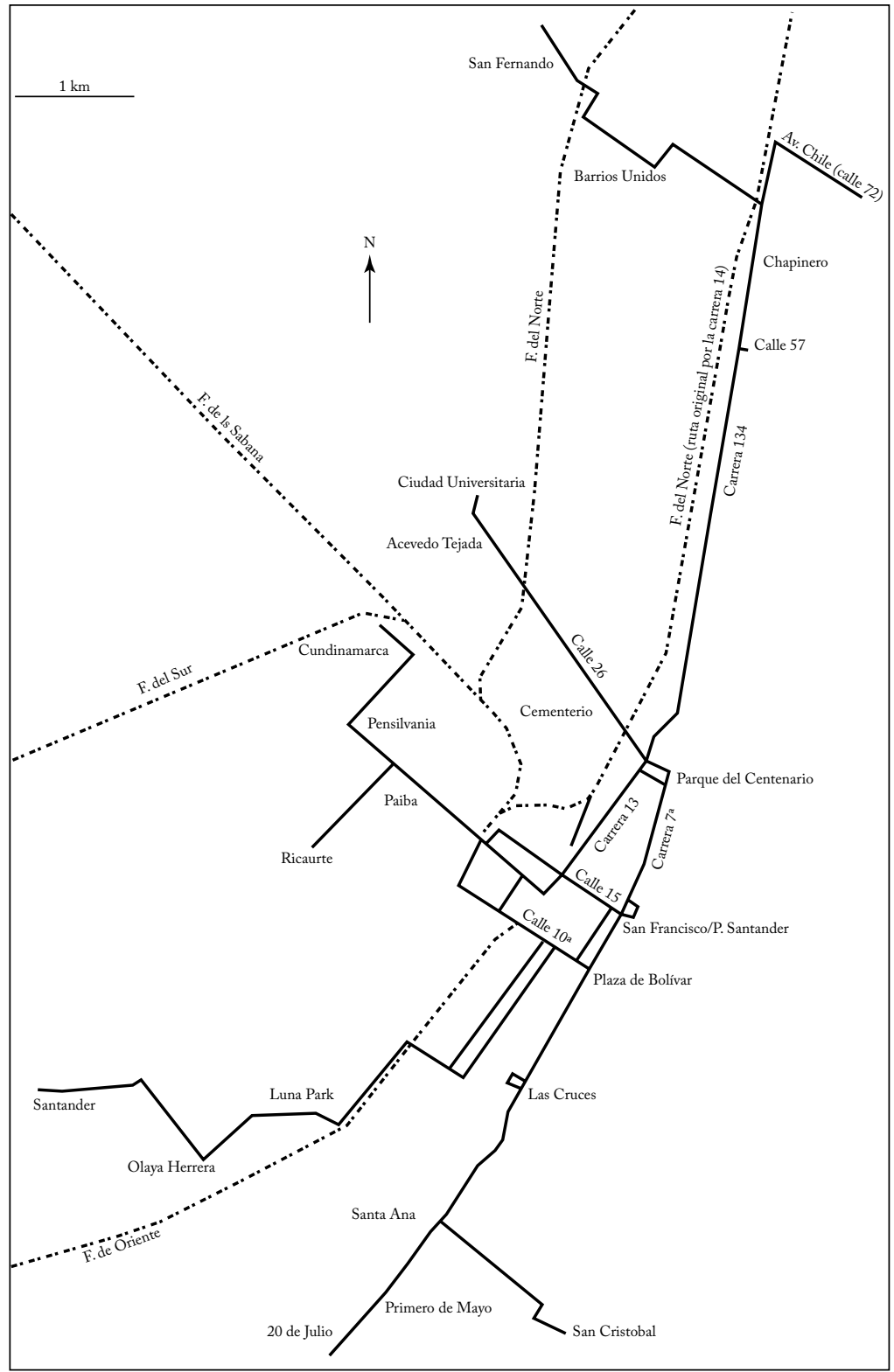

Fuente: Morrison (2007), modificado por los autores.

Revista de Economía Institucional, vol. i9, n.o 36, Primer semestre/2oi7, pp. $203-229$ 
Por su parte, en mayo de 1948 el alcalde Fernando Mazuera ordenó en forma perentoria que se levantaran los rieles de la carrera 7. a entre las calles 7.a y 15 , a lo que se oponían los miembros de la junta del acueducto y del tranvía ${ }^{8}$. Mazuera ordenó a los contratistas que cubrieran esta sección de la ruta, hasta el Parque de San Diego, con una capa de pavimento de 10 centímetros, incluso por encima de los rieles en algunos lugares, antes de que la junta pudiera reaccionar (Baquero 2009, 185). Además, las compañías de buses lograron que el tranvía no operara en la carrera 7. a entre la calle 26 y San Agustín, que esta ruta fuese entregada a empresas privadas y obtuviesen exenciones tributarias para importar equipos y repuestos (Aprile, 1983, 94-95).

En 1949, de las 14 rutas de la empresa 9 se atendían con tranvías, 2 con trolleys y 3 con buses de gasolina. Las cooperativas privadas tenían 500 buses en operación y el tranvía 103 en total. En los cinco años siguientes, las empresas municipales mantuvieron ese número y las empresas particulares 813 buses en promedio (Rodríguez y Núñez, 2003, 136).

Entre 1949 y 1952 la empresa del tranvía importó 20 trolleys y 22 buses que sustituyeron en parte a los carros del tranvía, y que ayudaron a desplazarlos del servicio (Jaramillo y Parias, 1995, 7272). En esos días, la tarifa del tranvía por fin se elevó a 6 centavos y la de buses y trolleys se fijó en 10 centavos, aunque ese aumento no generaba ingresos suficientes para superar el déficit operativo de los tranvías (ibíd., 74). No deja de ser curioso que el alcalde Mazuera participara en un "desfile" para celebrar la llegada de 60 buses nuevos de la Cooperativa de Buses. Y que fuese acompañado por el presidente del Concejo, Agustín Bernal, el Director Nacional de Transportes y Tarifas, José María de Guzmán, y el Director General de Circulación y Tránsito, Alfredo Ángel (Aprile, 1983, 98).

Así, en los últimos 10 años de operación la empresa aumentó los carros del tranvía en un $24 \%$ mientras que los pasajeros aumentaron en un 57\%, evidenciando un déficit de capacidad instalada más que de eficacia en la gestión, pues no podía aumentar la frecuencia del servicio debido a que las calles no eran de doble vía y ponían límites operativos. Esto, junto con la limitada expansión de la red de carrileras, fue expresión de un sistema que no adaptó su infraestructura a los cambios en la ciudad y que prestaba el servicio con un parque relativamente menor al final de la década. Además, los buses y trolleys

\footnotetext{
${ }^{8}$ En 1948 compuesta en su mayoría por representantes del Banco de la República, el Banco de Colombia, el Banco Central y la Caja Colombiana de Ahorros.
} 
daban un servicio más flexible con mayor capacidad de respuesta, aunque no necesariamente con un mejor servicio.

En los últimos 3 años de operación, luego de los hechos del 9 de abril de 1948 y del levantamiento de rieles por orden del alcalde Mazuera, se llevó a cabo el paulatino cierre de otras rutas y el levantamiento de rieles en otros tramos. Los últimos 8 carros del tranvía transitaron el 30 de junio de 1951 en la línea que atendía los barrios Pensilvania y 20 de Julio. La ruta empezó a ser atendida el día siguiente por buses marca White. El final de la vida del tranvía apenas suscitó algún comentario (Prieto, 2005, 50; El Tiempo, 1951a y b).

\section{CONSIDERACIONES FINALES}

Bogotá fue pionera en el establecimiento de tranvías en Colombia. Si bien se percibe un anhelo de modernización al querer dotarla de un sistema similar al de Nueva York, en una pequeña ciudad transitable a pie y que carecía de las condiciones para introducir un sistema de transporte público semejante, con apenas 78.000 habitantes, sí indujo un cambio en el modelo de ciudad, de un área pequeña con alta densidad, de forma oval y construida al lado de los cerros orientales, a una ciudad lineal de forma semi oval con baja densidad, que incorporaría cada vez más a pobladores rurales en la dinámica urbana.

Ese anhelo se hizo posible con inversión extranjera; el capital estadounidense quedó a cargo de la concesión vial en 1884, con resultados que dieron lugar a quejas continuas por el mal servicio, la mala atención a diferentes zonas de la ciudad y por el lento proceso de expansión (de la infraestructura y el material rodante) que finalmente llevarían al boicot de 1910. Esta fase terminó con la compra a la compañía estadounidense y la municipalización del servicio.

Durante la primera fase de operación ocurrió un proceso de suburbanización hacia Chapinero, y la incorporación de nuevas áreas rurales a la dinámica urbana. La administración municipal (1910-1929) inició un lento proceso de ampliación del sistema, de electrificación y modernización, con el uso mixto de carros de pasajeros y de carga, pero sin cubrir todas las áreas de expansión urbana, en particular los barrios populares y obreros. No hay evidencia de un diseño explícito que conectara estas nuevas áreas con los nacientes barrios obreros y facilitara el traslado de pasajeros del lugar de vivienda al sitio de trabajo. Si bien se conectaron algunos sectores al sistema, esa conexión fue incompleta, y no se detecta una relación clara entre el diseño del sistema, la política industrial y los grandes negocios inmobiliarios de la ciudad. 
A lo largo de los años se acentuó la tendencia a usar los beneficios de la empresa para asignarlos a otras empresas de la ciudad o a otras necesidades de gasto. Esta práctica fue acompañada del uso de la empresa del tranvía para contratar préstamos de los que no era destinataria. El uso del tranvía por la ciudadanía era volátil, de modo que se registraban variaciones permanentes en la tasa de aumento (y reducción) del número de pasajeros. Además, no parece haber tenido un sentimiento de adhesión y de satisfacción con el servicio del tranvía, como muestran sus frecuentes quejas y protestas.

La empresa tuvo un proceso errático de modernización y gestión, con cambios permanentes en las formas de administración, hasta su larga fase final, entre 1929 y 1951, cuando estuvo en manos de los acreedores. Desde los años veinte en adelante, el tranvía enfrentó una competencia desigual por los buses de gasolina. Esa competencia llevó a que en 1942 y 1943 se decidiera no modernizar ni actualizar el sistema para dar primacía a los buses, hasta que los hechos de 1948 anunciaron el declive final del tranvía. Los propietarios de buses se organizaron en cooperativas que cada vez tenían mayor representación en el Concejo, desde donde ejercían fuerte presión para el cese del tranvía, que desapareció en 1951 debido a la cooptación de la corporación en beneficio de ese sector.

Aunque el tranvía funcionó y reportó utilidades durante la mayoría de los años en que estuvo en servicio, no fue un sistema de transporte que generara un fuerte sentido de satisfacción y adhesión. Si bien conectó algunos barrios populares y relativamente distantes con el centro y a este con algunas zonas industriales, esta conexión fue parcial y asimétrica, y no satisfizo cabalmente las necesidades de transporte de una ciudad en rápido crecimiento. Durante largos periodos la empresa fue un fortín político y esto afectó su operación; aunque los trabajadores ganaron capacidad de negociación, era muy limitada frente a la de la empresa y del gobierno municipal.

\section{REFERENCIAS BIBLIOGRÁFICAS}

1. Alcaldía de Bogotá. Régimen Legal de Bogotá D. C., 8 de agosto de 2016, [http://www.bogotajuridica.gov.co/sisjur/consulta_avanzada.htm].

2. Aprile G., J. El impacto del 9 de abril sobre el centro de Bogotá, Bogotá, Centro Cultural Jorge Eliécer Gaitán, 1983.

3. Arias de Greiff, G. La mula de hierro, Bogotá, Carlos Valencia Editores, 1986.

4. Arias de Greiff, G. Entrevista con J. S. Correa, Bogotá, 8 de julio de 2008. 
5. Baquero M., J. I. “Tranvía Municipal de Bogotá. Desarrollo y transición al sistema de buses municipal, 1884-1951”, tesis de grado, Universidad Nacional de Colombia, 2009.

6. Correa, J. S. "E1 Kiosko de la Luz en el Centenario de la Independencia”, Revista de Economía Institucional 12, 22, 2010, pp. 287-290.

7. Divall, C. y W. Bond, eds. Suburbanising the masses: Public transport and urban development in historical perspective, Aldershot, Ashgate Publishing, 2003.

8. Duquino R., L. G. "Tránsito de la sociedad rural agrícola a la sociedad urbana industrial en Bogotá durante las primeras décadas del del siglo xx", Perspectiva Geográfica 15, 2010, pp. 61-84.

9. Ebrey, J. "Half-holiday excursions and rambling clubs. How did leisure shape the mobilities of the early Twentieth Century?", C. Kopper y M. Moraglio, The organization of transport. A bistory of users, industry and public policy, Nueva York, Routledge, 2015.

10. El Correo Nacional. "Demanda ruidosa", 17 de octubre de 1890.

11. El Heraldo. "Pleito del tranvía", 14 de septiembre de 1890, p. 2.

12. El Tiempo. "E1 Dr. Hernando de Velasco gerente del tranvía", 23 de enero de 1929, pp. 1 y 12.

13. El Tiempo. "Suprimidos los últimos tranvías que estaban prestando el servicio", 1 de julio de 1951a, p. 7.

14. El Tiempo. "Ha muerto el tranvía, viva el bus", 2 de julio de 1951b, p. 7.

15. Esquivel, R. “Sociedad y transporte urbano en Bogotá, 1865-1950”, Memoria y Sociedad 1, 2, 1996, pp. 19-37.

16. Esquivel, R. "Economía y transporte urbano en Bogotá, 1884-1930", Memoria y Sociedad, 4, 1997, pp. 39-61.

17. Gutiérrez, E. Historia de Bogotá, siglo xix, vol. 2, Bogotá, Villegas Editores, 2007.

18. Jaramillo, S. y A. Parias. Vida, pasión y muerte del tranvía en Bogotá, Bogotá, Universidad de los Andes, 1995.

19. Leidenberger, G. La historia viaja en tranvia: el transporte público y la cultura politica de la Ciudad de México, México DF, Universidad Autónoma Metropolitana, 2011.

20. Martínez, A. y J. Mirás. “The conquest of urban mobility. The Spanish case, 1843-2012”, M. Moraglio y C. Kooper, eds., The organization of transport. A history of users, industry, and public policy, Nueva York, Routledge, 2015.

21. McKay, J. P. Tramways and trolleys: The rise of urban mass transport in Europe, Princeton, NJ, Princeton University Press, 1976.

22. Mejía P., G. Los años del cambio: historia urbana de Bogotá (1820-1919), Bogotá, CEJA, 2000.

23. Mirás A., J. "The Spanish tramway as a vehicle of urban shaping: La Coruña, 1903-1962”, Journal of Transport History 26, 7, 2005, pp. 20-37.

24. Montezuma, R., ed. Presente y futuro de la movilidad urbana en Bogotá: retos y realidades, Bogotá, Veeduría Distrital, 2000.

25. Montezuma, R. La ciudad del tranvía, 1880-1920, Bogotá, Universidad del Rosario, 2008. 
26. Morrison, A. "Electric transport in Latin America", Los tranvías de Bogotá Colombia, 2007, [http://www.tramz.com/co/bg/t/ts.html].

27. Ocampo, J. A. "La crisis mundial y el cambio estructural", Historia económica de Colombia, Bogotá, Planeta, 2007, pp. 233-269.

28. Ojeda Z., N. I. "E1 ferrocarril y la estructura lineal”, Bogotá, 18991938", Revista de Arquitectura 9, 2007, pp. 13-17.

29. Ortega, A. Ferrocarriles colombianos, vol. 2, Bogotá, Imprenta Nacional, 1923.

30. Pérez V., P. E. "Desarrollo cooperativo e inicio de la economía solidaria en Colombia", 2009, [http://wb.ucc.edu.co/institucional4/ files/2009/05/desarrollo-cooperativo-e-inicio-de-la-economia-solidario-en-colombia.pdf].

31. Pereira F., A. "Cachacos y guaches: la plebe en los festejos bogotanos del 20 de julio de 1910", Anuario Colombiano de Historia Social y de la Cultura 38, 1, 2011, pp. 79-108.

32. Pires, H. F. "Imagens e históia na Internet: os bondes, patrimônio brasileiro”,Ar@cne 156,2012, [http://www.ub.edu/geocrit/aracne/ aracne-156.htm].

33. Prieto, L. "La aventura de una vida sin control. Bogotá, movilidad y vida urbana 1939-1953", tesis de grado, Universidad Nacional de Colombia, 2005.

34. Quijano P., J. y J. Reyes G. Historia y doctrina de la cooperación, Bogotá, Universidad Cooperativa de Colombia, 2004.

35. Rodríguez, L. E. y S. Núñez. Empresas públicas de transporte en Bogotá, siglo xx, Bogotá, Alcaldía Mayor de Bogotá, 2003.

36. Santos M., E. "Y el tranvía de mulas quedó solo", El Tiempo, 12 de agosto de 2001.

37. Schmucki, B. "On the trams: Women, men and urban public transport in Germany", Journal of Transport History 23, 1, 2002, pp. 60-72.

38. Schmucki, B. "Fashion and techological change: Tramways in Germany after 1945", Journal of Transport History 31, 2, 2010, pp. 1-24.

39. Suárez M., A. M. La ciudad de los elegidos: crecimiento urbano, jerarquización social y poder político. Bogotá (1910-1950), Bogotá, Editora Guadalupe, 2006.

40. Tennet, K. "Management and competitive advantage in the public transport industry: York Corporation Tramways (1909-1934)", вAм Conference Proceedings, Londres, 2013, [http://www.bam.ac.uk/].

41. Zambrano, F. Historia de Bogotá siglo $x x$, vol. 3, Bogotá, Villegas Editores, 2007. 